to less than 100,000 metric tons per year, even at the highest forecasts of nuclear demand.

Different nuclear programmes would also affect the need for fuel enrichment facilities, and this is perhaps the most crucial issue raised by the report. A system using a mixture of light water reactors and fast breeders would show a steadily increasing need for enrichment facilities up to and beyond 2010. But if the system also included some fast converters, the demand for enrichment facilities would tail off by 1990 , and might show a small decline after that. If more pessimistic assumptions about the rate of growth of power demand are assumed, the need for enrichment facilities might actually decline quite sharply after 1990. This kind of argument can serve two purposes; first it can help to determine whether investment in enrichment is justified, and second it can show that, by carefully relating the systems chosen to the growth of demand, maximum use can be made of existing plant.

In fact, decisions about nuclear power plant are rarely made for such esoteric reasons. It is usually the generating costs which decide. But, although the survey is in this sense of academic interest, it reflects the kind of thinking which will increasingly have to be done, both by governments and utilities.

\section{Read Fewer Journals}

Two reports published recently confirm that a good coverage of a particular scientific subject can be obtained by reading a relatively small number of journals. One of the reports (Investigation on Nuclear "Core Journals", by E. Böhm, EUR 3887 e; 1968) is of a survey in the field of nuclear scienco and technology conducted by the Centre for Information and Documentation, run by Euratom in Brussels. The survey was based on articles abstracted by Nuclear Science Abstracts and by seventeen other abstracting and indexing services. The results show that 272 "core journals" (13.8 per cent) out of a total of 1,978 different primary periodicals produce about 75 per cent of the relevant articles in the nuclear field. Of these "core journals", nearly three-quarters ( $73 \cdot 3$ per cent) came from the United States, Canada and Western Europe; 22.2 per cent from the Soviet Union and Eastern Europe; and the remainder (4.7 per cent) from other countries. The top journal was the Bulletin of the American Physical Society with 961 citations in the abstracting journals. This was followed by The Physical Review (504 citations), Transactions of the American Nuclear Society (378 citations) and Physics Letters (288 citations). Nature, the first British journal in the list, came seventh in the list with 223 citations.

Another recent post-mortem on journal literature, this time in the wider field of physics, has been published by the American Institute of Physics (Journal Literature Covered by Physics Abstracts in 1965, by $\mathrm{S}$. Keenan and F. G. Brickwedde, $I D$ 68-1; 1968). It is a sequel to a similar report published in 1961. Some information from the earlier survey is included in this latest report to show the pattern of development of physics literature over the five-year period.

The results are interesting though not, perhaps, surprising. Compared with the 1961 figures the number of journal articles in 1965 increased by 60 per cent (a total of 32,279 articles from 495 journals were collected). The number of journals abstracted in 1965 , however, only increased by $22 \cdot 2$ per cent. This shows that the growth of Physics Abstracts has been caused by the increasing number of scientific papers in the most productive primary journals over the past five years. These journals are published by the prineipal contributing countries - the United States ranks first with the highest number of abstracts, and the largest number of journals (93); Britain ranks third behind the Soviet Union in the number of abstracts, but it is second in the number of journals abstracted (92). The report notes the substantial increase in the number of papers published in the Netherlands-probably explained by the publication there of several productive "international" journals. A point the report makes, but does not attempt to explain, is the increase in the number of Japanese journals covered by Physics Abstracts between 1961 and 1965, but without a corresponding increase in the number of abstracts - there was in fact a decline.

The pattern that a few journals generate a high proportion of the total number of papers is found in physics as in nuclear science and technology and other subjects. In Physics Abstracts 1965, 75 per cent of the abstracts were generated by 60 journals or only $12 \cdot 1$ per eent of the number of journals (495) abstracted. In the ranked list, The Physical Review comes first, followed by Journal of Chemical Physics and Physics Letters. Nature again heads the British journals, coming sixteenth in the league table.

\section{Cheerful Aslib}

THE present financial climate certainly does not yet seem to have affected the fortunes of Aslib. Indeed, the impression given from its annual report for 1967 is that the association is flourishing, with its gross income reaching a record level of $£ 137,002$, an increase of 10 per cent over 1966. Members' subscriptions rose and, with extended financial support from the Office for Scientific and Technical Information (OSTI), research activities were expanded. Expenditure on research and consultancy during the year rose from $£ 21,618$ to $£ 37,808,65$ per cent of this being covered by grant and special project funds from OSTI.

The research department, with a staff of eighteen, brought four projects almost to completion during 1967 - on the literature of plasma physics, the identification and ranking of UK journals carrying original scientific work, surveys of the use of technical libraries, and the use of social science literature; and six new projects were begun. Two of these new projects involve surveys of the forms and uses of bibliographic records in British libraries, and information services in metallurgy. 'The first of these two surveys will give valuable background information for the planning of the availability of bibliographical data in a form that can be read by machines.

Now that the Government is becoming better aware of the importance of information services in the economy, it is natural that Aslib should have been asked by the Government to assist the Dainton Committee in its deliberations over the functions and organization of a national library system. The comments of Aslib on the points raised by the Dainton Committee and on other matters relating to the requirements of a national library are published in Aslib Proceedings, 20 (7); 1968.

In principle, Aslib's recommendations are similar 
to those suggested by the Library Association, and reported in Nature (218, 1196; 1968), although they are much less positive and, because of the functions of the two associations, different emphasis is placed on different aspects of the problem. Like the Library Association, Aslib wants to see a coordinated National Library Administration (what the LA calls a National Library Service). This should cover the present library departments of the British Museum, the National Reference Library of Science and Invention, the National Lending Library and the National Central Library, but should not include the Science Museum Library. The administration is seen as a subunit of a future National Information and Library Authority, supported probably by the Department of Education and Science. As to the location of the National Library, the memorandum suggests that central London is the best place for either a unified system (reference and lending), or for the reference function of a dual system. The future of Aslib itself is seen alongside the National Library where its resources and experience could be used for the study and development of operational systems. This suggestion agrees with one made in the Library Association report on Scientific Library Services (see Nature, 21\%, 216; 1968).

The Aslib memorandum is a rather inconclusive document, principally because it admits to the lack of knowledge on user requirements and cost and effectiveness relationships of the possible organizational structures. And Aslib seems to disagree with the Library Association about the linkage of the museum collections and the library departments of the British Museum. The librarians came out strongly for the separation of the antiquities and the books, but Aslib seems to be completely uncommitted.

\section{Security at Stonehenge}

The prehistoric Indian dwellings in the Mesa Verda National Park in Colorado and rock formations in several other National Parks, including Bryce Canyon in the south-west of America, are said to be suffering damage from sonic booms-although, to be fair, the Defense Department vigorously denies any connexion between the damage that is undoubtedly occurring and sonic booms caused by military aircraft. In Britain, the monuments under the care of the Ministry of Public Building and Works face damage of a much more mundane kind-vandalism, souvenir hunting and casual damage by visitors. Like any other curator, the ministry has to balance the legitimate demands of the public to see its monuments with the need to preserve them for posterity. The system of having a curator on the site when it is open, and prohibiting access at night, provides adequate protection for most of the monuments, but the exception is Stonehenge, which is a source of continual problems.

The turf at Stonehenge is relatively safe, now that the Druids have given up their former practice of burying ashes under it, and during the day with a curator in attendance the monument is fairly safe. The children and adults who clamber over the stones behind the curator's back may give the impression of literally treading Stonehenge into the ground, but, according to the ministry, they do little real damage. It is during the night that the real harm is done. The ministry is loth to fence Stonehenge off for aesthetic reasons - and to do so would be to admit that all the existing protection was inadequate. For some curious reason, however, Stonehenge attracts university rag committees, supporters of the Campaign for Nuclear Disarmament and people who enjoy spending their evenings painting the stones with slogans. The last case was on the night of February 20-21 this year, when seven stones were daubed with yellow paint. The problem is that the paint penetrates so deeply that cleaning would cause irreparable damage to the surface of the monument. As a result of this continual vandalism the ministry has, since February, started new security measures during the night and even stricter precautions are being planned. These, like all the best sccurity arrangements, must obviously remain secret.

Preventing the daubing of Stonehenge is not, of course, simply a matter of aesthetics. As recently as 1956 the very faint carving of a dagger was discovered by a visitor who chanced to look up at one of the stones in unusual light conditions. If there are any other such carvings, they could be important clues to the origin of Stonehenge, which still remains obscure.

\section{Astronomical Hardware}

OPTICAL astronomers are turning increasingly to the techniques of instrumentation to get the most from

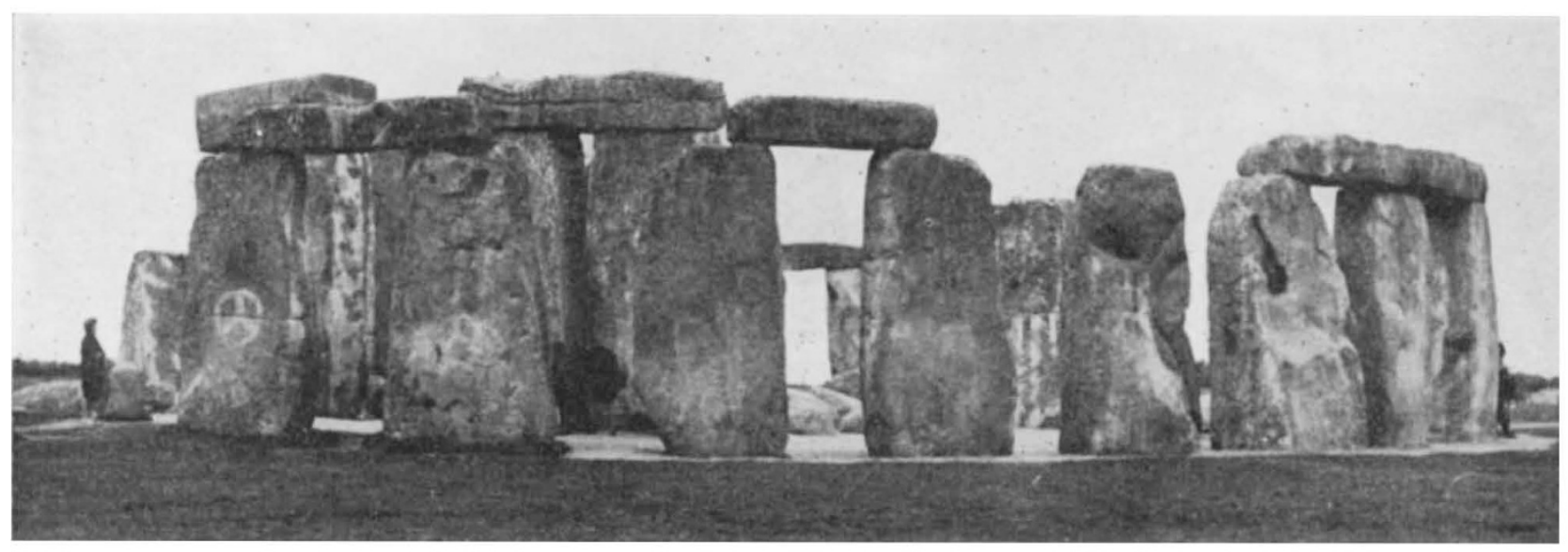

